
ДВИГАТЕЛЯ В ФАЗНЫХ КООРДИНАТАХ

\title{
MODELING OF ELECTRIC SYSTEM ASYMMETRICAL STATES WITH
} ASYNCHRONOUS LOADS

\begin{abstract}
Аннотация. Для управлении режимами современных электроэнергетических систем, в которых применяются технологии активно-адаптивных сетей или smart grid, необходимы методы и алгоритмы для моделирования режимов, обеспечивающие корректный учет узлов нагрузки.

В докладе представлены методы моделирования узлов асинхронной нагрузки, реализованные на базе фразных координат.
\end{abstract}

Ключевые слова: моделирование и идентификация узлов нагрузки.

Abstract. Work provide a method for modelling and identificate parameters of electrical load to control the status of electric power system with actively adaptive networks.

Keywords: parametrical identification of asynchronous loading.

Нагрузка в виде совокупности асинхронных электродвигателей имеет небольшое сопротивление обратной последовательности. За счет этого фактора создается симметрирующий эффект, заключающийся в снижении несимметрии в узле подключения асинхронной нагрузки (АН). Для учета этого эффректа требуется разработка моделей узлов АН, обеспечивающих корректный учет этого эффекта. Такие методы могут быть реализованы путем перехода от традиционных технологий, базирующихся на симметричных составляющих, к алгоритмам, использующим фразные координаты узловых напряжений [1-6].

Исследования, результаты которых представлены в работах [1-5], показывают, что с помощью моделей АН в фазных координатах удается адекватно учитывать симметрирующий эффект, создаваемый асинхронными электродвигателями. Однако для практического применения этих моделей необходима точная информация о параметрах $\mathrm{AH}$, которые отвечают схемам замещения для прямой и обратной последовательностей. Результаты количественного анализа показывают, что при определении этих параметров по справочным данным разные методики могут давать отличающиеся результаты.

Наиболее эффрективный подход к определению схемных параметров для большой совокупности асинхронных электродвигателей, подключенных к мощному узлу АН, состоит в использовании методов параметрической идентификации [3, 4]. Эти методы обеспечивают высокую точность расчета несимметричных режимов электроэнергетических систем с узлами асинхронной нагрузки. 
Данный тезис подтверждается результатами компьютерного моделирования, представленными на рисунке 1. Из этого рисунка видно, что погрешности в определении модулей напряжения зависят от класса точности измерительных приборов, применяемых при идентификации. Однако, даже для приборов класса 1, величина погрешности не превышает долей процента.

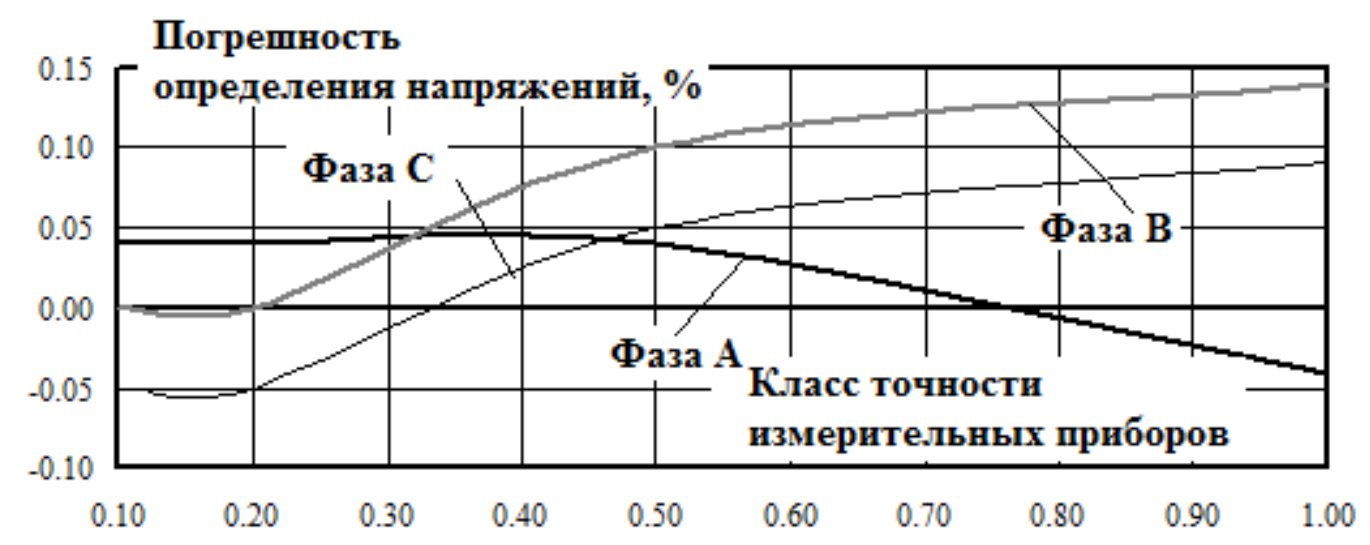

Рисунок 1 - Зависимость погрешностей от точности измерений

На основании изложенного можно сделать вывод о том, что модели узлов асинхронной нагрузки, сфрормированные по результатам параметрической идентификации, обеспечивают высокую точность моделирования несимметричных режимов электрических сетей с мощными узлами асинхронной нагрузки.

\section{ЛИТЕРАТУРА}

1. Закарюкин В.П., Крюков А.В., Ле Конг Зань. Моделирование и параметрическая идентификация узлов нагрузки электроэнергетических систем. Иркутск : Изд-во ИРНИТУ, 2016. 158 с.

2. Закарюкин В.П., Крюков А.В., Ле Конг Зань. Идентификация асинхронной нагрузки // Системы. Методы. Технологии. № 2(22). 2014. С. 56-61.

3. Закарюкин В.П., Крюков А.В., Ле Конг Зань. Определение параметров асинхронной нагрузки // Вестник ИрГТУ. № 6 (89). 2014. С. 172-178.

4. Закарюкин В.П., Крюков А.В., Ле Конг Зань. Параметрическая идентификация узлов асинхронной нагрузки с частотно-регулируемыми электроприводами // Вестник ИрГТУ. № 4 (99). 2015. С. 157-165.

5. Andrei Vasilevich Krukov; Vasili Panteleimanavich Zakaryukin; Lê Công Danh. Tính toán tải của động cơ không đồng bộ khi mô phỏng trạng thái không đối xứng của hệ thống truyền tải điện // Tạp chí Khoa học kỹ thuật quân sự - Journey of Military Science and Technology. ISSN 2354-1288. Số 7 - T4/2015. pp. 72-77.

6. Коновалов Ю.В., Дудко А.А. Исследование свойств генерирующих электротехнических комплексов // Повышение эффрективности производства и использования энергии в условиях Сибири. Иркутск. 2014. В 2-х т. Т. 1. С. 88-92. 